\title{
Leisure-time and subjective well-being among park visitors in urban Pakistan: the mediating role of health satisfaction
}

\author{
Khadija Shams ${ }^{1,2} \cdot$ Alexander Kadow ${ }^{1,3}$
}

Received: 1 February 2021 / Accepted: 23 May 2021

(c) The Author(s), under exclusive licence to Springer Nature Switzerland AG 2021, corrected publication 2022

\begin{abstract}
The aim of this paper is to explore the importance of health satisfaction with a particular emphasis on how leisure-time spent in parks determines the overall wellbeing, including the health satisfaction among the park visitors. Our data have been collected from park visitors in four major public parks in urban Pakistan based on a multistage non-random sampling technique. The results from the regression analysis suggest that besides socio-economic characteristics like being well-educated and richer; the amount of weekly leisure-time spent in park plays a positive and significant role in well-being. In particular, health satisfaction mediates the relationship between the amount of weekly leisure-time spent in park and subjective well-being among the park visitors in the study area. Policy makers should hence put more emphasis on park facilitation to encourage park visitation to ensure greater happiness and better quality of life particularly in terms of health satisfaction. This in particular pressing as developing countries increasingly grapple with adverse health effects stemming from Covid-19.
\end{abstract}

Keywords Leisure-time · Happiness · Health satisfaction · Pakistan · Quality of life · Subjective well-being $\cdot$ Urban parks

Khadija Shams

kshams2008@gmail.com

Alexander Kadow

kadow@fb3.fra-uas.de

1 Department of Economics, University of Glasgow, Glasgow, UK

2 Department of Economics, Shaheed Benazir Bhutto Women University, Peshawar, Pakistan

3 Department of Economics and Law, Frankfurt University of Applied Sciences,

Frankfurt am Main, Germany 


\section{Introduction}

Park and recreation facilities have long been associated with having a positive impact on happiness for over a century; still research on the relationship of parks with happiness and health satisfaction is limited, particularly from a social psychological perspective. Given that park activities and happiness are aspects of leisure and subjective well-being (SWB), respectively, yet the literature has focused tangentially through the investigations of leisure and subjective well-being. The aim of this paper is to identify the association between leisure-time spent in the parks and subjective well-being in relation to health satisfaction of the park visitors in urban Pakistan. ${ }^{1}$ The present research will contribute to the existing happiness literature by introducing the leisure-time spent in park by a park visitor as a predictor of his/her health satisfaction.

Parks and green spaces have many health, social, economic and environmental benefits to society. Successful parks pay dividends for cities in building civic pride, increasing tourism, economic investment and contributing to health and the quality of life (Assali 2015). World Bank (2013) reported that Pakistan is facing many environmental issues including air pollution, noise pollution, water pollution and health deterioration of populations. Sanchez-Triana et al. (2014), argue that the increase in urbanization, industrialization and motorization are likely to intensify these issues.

Parks and open green spaces provide many opportunities for physical activities and social interaction which result in the enhancement of health and social cohesion, hence

improving the quality of life. High quality, well-designed parks and urban public spaces play a positive role in promoting individual well-being and in enhancing social, economic and environmental value of towns and cities (Beck 2009).

Parks and green spaces encourage a variety of physical activities, for instance: walking, cycling, dog walking, sports and children active play, etc. Research studies show a positive relationship between parks and healthy life. Parks and green spaces have physical and mental health benefits to the users. They reduce stress and provide mental satisfaction as well as physical health benefits (Koohsari et al. 2015). Gies (2006) in his study on US data found that people who engage in regular physical activity benefit from reduced risk of premature deaths; hypertension, colon cancer, non-insulin-dependent diabetes; improved maintenance of muscle strength, joint structure, and joint function; reduced body weight, favorable redistribution of body fat; improved physical functioning if they suffer from poor health; and healthier cardiovascular, respiratory, and endocrine system. Urban parks play a significant role in the provision of ecosystem services and recreational activities, contributing to improving the quality of life and welfare of local residents (Kaczynski and Henderson 2007; Koramaz and Türkoglu 2018).

\footnotetext{
1 In the remainder the terms: "Subjective well-being", "Happiness" and "Quality of Life" have been used interchangeably. According to Diener (2009), Subjective Well-Being (SWB) including happiness, life satisfaction, and quality of life encompasses various socio-economic and demographic variables such as age, gender, education, income, health, social contact, activity, and personality.
} 
Health involves physical health and mental health. Physical health can be improved by physical activity and mental health by the reduction of stress for mental satisfaction. Health is considered as a primary predictor of quality of life. There are many definitions for the term quality of life suggested by the broad literature on the concept of quality of life. Quality of life is a holistic life experience obtained through the combination and interaction of different domains of life. The quality of life is defined as the satisfaction derived from health benefits, social benefits, personal benefits, and environmental benefits (Koramaz and Türkoglu 2018).

Many studies are conducted in developed countries and fewer in developing countries to examine the benefits of parks and open green spaces and their contribution to the quality of life and health. However, the evidence for the links between health and well-being, and urban parks/urban green space is unclear (Lee and Maheswaran 2011; Lee, Jordan \& Horsley, 2015). This paper aims to track the leisure-time spent in urban public parks in relation to the park visitor's health satisfaction and overall well-being in pure subjective terms, with special reference to Pakistan.

\section{Research objectives}

Our main objective of the study is to explore a relationship between the leisure-time spent in parks and subjective well-being of the park visitors. Second, using econometric techniques, we try to identify a relationship between the amount of leisuretime spent in parks and the health satisfaction of the park visitors.

\section{Research question}

Does the health satisfaction mediate the relationship between leisure-time and subjective well-being among the park visitors in the study area?

\section{Literature review}

High quality, well-designed parks and urban public spaces have positive social, economic and environmental effects on the communities. Good quality of public spaces improves quality of life such as health, safety and economic well-being. Good quality of parks seems of particular relevance for strong and long-lasting communities. According to Market and Opinion Research International (MORI) company's research published by Commission for Architecture and the Built Environment's Public Space Unit/CABE Space (2004) nearly 91\% of those surveyed believe that good quality parks and open spaces improve their quality of life and $74 \%$ of people say that better quality parks and open spaces are important for people's mental health and physical well-being. CABE Space is a specialized unit within the Commission for Architecture and the Built Environment (CABE). It aims to bring excellence in the maintenance of parks and urban public spaces in towns and cities of England. There are 34 national datasets analyzed by the researchers to show the link 
between the quality of life and the quality of public space. Regression analysis was used to show the nature and strength of the relationship.

In this review, health effects are looked at the broadest sense to cover physical health as well as mental health and the overall well-being. Similarly, Li (2020) suggest that frequency of visits to urban parks and length of stay in urban parks have positive effects on the self-reported quality of life. The author added that green spaces such as urban parks are associated with people's health and wellness, including their quality of life (QoL). In contrast, Lee and Maheswaran (2011) in a meta-analysis conclude that the evidence for the park use and health as well as well-being relationship is weak. This is reiterated in the later Lee et al. (2015) study. The authors argue that environmental factors such as the quality and accessibility of green space affect its use for physical activity.

Physical activity is very important for good health but not all parts of the population have equal access to physical activity facilities and resources. Ethnic minorities and low-income communities suffer from physical inactivity, obesity and many other chronic diseases, as they lack adequate access to parks and green spaces or public recreation services. This is an issue of environmental justice (EJ). It is a social injustice. There is a need for fair treatment. Racial and ethnic differences or injustices are increasing in US minorities. It is a national goal to remove the socio-economic disparities of racial minorities and low-income population to improve their health and quality of life (Taylor et al. 2007). Mitchell and Popham (2008) observed that parts of society with greater exposure to green spaces have lowest levels of health inequalities related to income deprivation.

Beck (2009) concluded that the quality of public spaces, maintenance, user experience, ecological quality have positive associations with people's quality of life. Hussain et al. (2010) using survey data for Pakistan suggest that public parks improve the quality of life. Parks make the surroundings beautiful. There are environmental, social, personal, and health benefits of parks to community. Parks are used for amusement, relaxation, enjoyment and recreational activities. They provide a feeling of security and freedom from noise and pollution. They are also used in terms of meeting places to get socialize with people.

Nasution and Zahrah (2014) conducted a survey to identify the relationship between public open spaces (POS) and quality of life (QoL) factors. The survey was conducted for four active public spaces in Medan, Indonesia. The factors of quality of life were health, recreation, and urban environment. By using five-point Likert scale, the level of satisfaction with the factors of POS and QoL was quantified and analyzed through Spearman correlation. It was found that there is a significant and positive relationship between public open space and quality of life. Having factor analysis, the study found that the most significant factors of POS and QoL were function factor and health factor, respectively. It was concluded that public open spaces have positive health effects.

Hajmirsadeghi (2012) argued that urban parks are very important in urban planning. They make the city sustainable by making the city livable, pleasant and attractive for its citizens. Parks and green spaces provide social services which are essential to the quality of human life. A survey was conducted in Iran, in summer 2009, among the visitors of the most popular park of Qazvin (The Mellat). Both 
quantitative and qualitative techniques were used to collect data from the respondents. Data were quantified using descriptive statistical techniques. The results showed that majority of the people visited the park to relax.

The feelings and emotions caused by visiting the park have a significant contribution to their well-being. It was concluded that urban parks have environmental and social benefits which make the quality of life better and hence develop a sustainable city. Many research studies provide evidence that public open spaces such as parks and green spaces encourage a variety of physical activities like walking, cycling, running, dog walking, sport or active children play. However, there are some inconsistencies among studies examining the relationships between different aspects of public open space (such as access to, size, design features and quality) and physical activity participation, which make it difficult for urban designers and policymakers to design public open space. It is possible that the variations in the studies are contextual or cultural. Many conceptual and methodological gaps have also been identified which can help in designing public open spaces and promoting physical activities (Koohsari et al. 2015).

Larson et al. (2016), using 2014 data from 44 U.S. cities, estimated the relationship between urban park quantity (size), quality/designed features, and proximity and Gallup-Healthways Well-being Index/WBI (i.e. the aggregate self-reported scores on five different domains, e.g., physical, community, social, financial, and purpose). The authors found that park quantity or size (measured as the percentage of city area covered by public parks) was among the strongest predictors of overall well-being in general and the strength of this relationship is particularly driven by parks' contribution to physical and community well-being. In contrast, the study did not find significant relationships of park quality and park accessibility with the wellbeing, respectively. The results suggest that expansion of urban parks may help to achieve health benefits and well-being in cities and to improve urban quality of life.

Many research studies conducted in developed countries provide evidence that parks stimulate physical activity and have positive health benefits. Liu et al. (2017) examined this relationship in the context of a developing country, China. It was found that park users were more active in all forms of physical activity, except transport walking, than non-users. Furthermore, the distance to a park within $500 \mathrm{~m}$ from residence and park use were significantly and positively associated with total physical activity. Overall, the study found a positive correlation of physical activity in parks with social, environmental and mental health benefits.

Physical activity is very necessary for health and quality of life. Health benefits are proportional to the amount of physical activity involvement. Physical inactivity is the cause of obesity that leads to severe chronic diseases which can be very costly. Obesity and overweight are the cause of 300,000 deaths per year in the US. Easy access to parks increases physical activity and reduce obesity. It was found that residents of Los Angeles who lived near the park were more involved in physical activity than those who lived far from green spaces. Unfortunately, many Americans lack access to parks or recreational facilities. Parks and greenways reduce air pollution, global warming, accidents, and mental stress. Parks provide opportunities for playing and brain development of children. Parks make the communities more livable thus improving the social health (Gies 2006). 
According to Koramaz and Türkoglu (2018) urban parks are considered as one of the determinants of Quality of Life (QoL). Urban parks contribute to improving QoL in cities by promoting health and physical activity. Easy access and availability to parks for physical activity in residential environment, and support or encouragement through social relations among the residents contributes positively to overall QoL. The study provides insights for policies that contribute to improving QoL in cities in the context of urban parks' role. Maller et al. (2009) relate contact with nature, in a park context, with the health benefits of the park users. Van Herzele and de Vries (2012) observe that people living in greener neighborhood report greater happiness than those living in less green neighborhood in terms of visual proximity of green spaces or greenness from the street and the home.

Sturm and Cohen (2014) investigated the impact of proximity to urban parks on mental health. The study was based on a secondary data collected for an assessment of park improvements conducted between January 2004 and March 2008 in the city of Los Angeles, California. The data were reanalysed at the individual level. The authors used regression analysis to estimate the relationship between the mental health (as dependent variable) measured by the five-question Mental Health Inventory (MHI-5) score, ranges from 0 to 100 (i.e. from lowest to optimal), and residential distance from parks (the main independent variable); while controlling for individual characteristics of the sample. The data were stratified by residential distance from the parks. The findings of the study suggest that mental health is significantly related to residential distance from parks, such that longer walking distances from parks decrease mental health or vice versa. The number of visits and physical activity minutes are positively and significantly related to mental health, however controlling for them does not affect the association between mental health and distance from park.

Summing up, given the quality and quantity of parks, park use and well-being are positively related. The purpose of such a literature is to identify not only what is known, but also particularly what is not known from a non-Western source and/ or to identify the weakness of the existing research. The present research is designed for a developing and predominantly Muslim country of Pakistan to overcome weakness or fill gaps in the existing research.

\section{Data and methodology}

\section{Research design}

The data has been collected from the park visitors by means of a survey which took place in 2019 with a total sample size $n=400$. Park visitors have been selected within four major urban parks across the cities in Pakistan's provinces. In all cases, the corresponding provincial capital city has been included in the sample (multistage non-random sampling). In the first stage of sampling we selected the pre-determined capital cities for each of the province of Pakistan to ensure a good representation of urban population in the country. In the second stage, we selected a park from each of the capital cities based on its location. For instance, we chose those parks 
which were located nearest to the center of the given cities. In the third stage, the sample was distributed according to age and gender of the park visitors in each of the selected parks. For instance, the age criterion for the park visitors to be included in the sample was 16 years or above which referred to the adult population only. Secondly, to be in line with the country's overall population shares, a fixed quota of male $(51 \%)$ and female $(49 \%)$ was set for sample allocation according to the gender of the park visitors in each of the selected parks. The total sample size has been chosen in line with the Yamane formula and is based on the population size of urban Pakistan. ${ }^{2}$ We have allocated the sample size equally across the four urban parks in the capital cities of Pakistan's four provinces to increase the regional scope of the study. The parks selected in each province are: Kachnar Park in Islamabad (province of Punjab), Jheel Park in Karachi (province of Sind), Garrison Park in Peshawar (province of Khyber Pukhtunkhuwa/KPK) and Askari Park in Quetta (province of Baluchistan). A total of 100 visitors (i.e. $25 \%$ of the total sample) from each park have been selected based on quota sampling (i.e. quotas of men and women, approximately $50 \%$ each). The survey was conducted using a detailed questionnaire to have a differentiated picture in terms of subjective well-being (SWB), health satisfaction (HS) and park visitation (in terms of leisure-time spent in the park per week) and the respondents' characteristics. The leisure-time includes any kind of activity such as walking, jogging, exercise, enjoying green spaces and the nature, and socializing. The questions were asked to the park visitor/respondent to collect first-hand data on various socio-economic and demographic variables. All respondents refer to the age group of 16 years and above. Furthermore, given the micro-level nature of this study, the results are based on individual happiness instead of an aggregation of the individual happiness.

\section{Descriptive statistics}

Our survey provides data on health, leisure and other variables like income, family size, education, marital status, ethnic background, age and sex of the parks visitors. The visitor's health satisfaction (HS) is determined by asking the following question to the park visitor: "How happy are you with your current overall health status?" The overall health involves both physical and mental health. The answers were recorded in an ordinal scale from 1 to 4, where 1 is coded as "Not at all happy", 2 as "Less than happy", 3 as "Rather happy" and 4 as "Fully happy". The measure of subjective well-being (SWB) is based on the following question to the park visitor: "How happy are you with your current overall quality of life? Answers were reported on the ordinal scale ranging from 1 to 4, where 1 is coded as "Not at all happy", 2 as "Less than happy", 3 as "Rather happy" and 4 as "Fully happy" to assess the overall well-being. We follow the literature on the Economics of Happiness by considering

\footnotetext{
${ }^{2}$ The Yamane formula for determining the sample size is given by: $n=N /\left(1+N \mathrm{e}^{2}\right)$, where $n$ sample size, $N$ population size, and $e$ Margin of error $(\mathrm{MoE})=0.05$ based on the research condition (Yamane 1967). The size of the urban population in Pakistan is estimated to amount to about 76 Million (CIA 2019).
} 
Table 1 Descriptive statistics of park visitors' health satisfaction and subjective well-being measures

\begin{tabular}{lll}
\hline & Well-being measures & \\
& Health & Subjective \\
& Satisfaction & Well-being \\
& $(H S)$ & $(S W B)$ \\
& $(1-4)$ & $(1-4)$ \\
\hline Mean & 2.70 & 2.63 \\
Standard deviation & 0.94 & 1.03 \\
Frequency of value & & \\
1 & $10 \%$ & $18 \%$ \\
2 & $32.5 \%$ & $25 \%$ \\
3 & $35 \%$ & $35 \%$ \\
4 & $22.5 \%$ & $22 \%$ \\
\hline
\end{tabular}

Source Survey 2019

SWB as a holistic concept capturing all domains of human life, e.g. health, wealth, and leisure, etc. (Bruni and Porta, 2005, 2007). Our well-being metric indeed might have some overlap with Satisfaction With Life Scale (SWLS) indicator which has a good reliability and validity (in the spirit of Pavot and Diener 2008).

Table 1 illustrates the concept and provides some descriptive statistics of the park visitors' health satisfaction and subjective well-being measures. The health distribution is skewed towards the higher health scales with the mass of the distribution being concentrated on that side. For instance, the given distribution shows that $22.5 \%$ and $35 \%$ of the observations are reporting higher health satisfaction (HS) scales, i.e. 4 and 3, respectively. This means that more than half of the population (i.e. $57.5 \%$ ) is observed at the higher health scales. Similarly, the distribution of SWB metric also suggests that $22 \%$ and $35 \%$ of the observations are at higher SWB scales, i.e. 4 and 3, respectively. That implies that more than half of the population (i.e. 57\%) is reported at the higher SWB scales. This suggests an overall similar distribution of health satisfaction and subjective well-being scales.

Table 2 provides descriptive statistics of the socio-demographic variables for the sample analyzed in this study. The gender distribution of the sample was reasonably balanced (51\% male and $49 \%$ female) and well in line with Pakistan's overall population shares. ${ }^{3}$ The average age of the park visitors was reported as 38 years. The sample had mean leisure-time of 35 min spent in the parks per week, approximately. However, the average weekly leisure-time of park use was more for males (40 min) than for females (30 min). The respondents' education level amounts to 12 years of schooling on average, which shows that mostly educated people visit regularly to the parks. The average number of children per household was observed to be

\footnotetext{
3 According to the Pakistan Bureau of Statistics (2017), the share of men in Pakistan's total population amounts to $51 \%$, while women represent $48.76 \%$ of the population (with transgender forming $0.24 \%$ of the total population of Pakistan).
} 
Table 2 Descriptive statistics of the socio-demographic variables

\begin{tabular}{lllll}
\hline Socio-demographic variables & \multicolumn{2}{l}{ Percentage (\%) } & & \\
\cline { 2 - 4 } & or & & & \\
\cline { 2 - 4 } & Mean & Min & Max & SD \\
\hline Male & $51 \%$ & - & - & - \\
Female & $49 \%$ & - & - & - \\
Married couple & $48 \%$ & - & - & - \\
Age in years & 38 & 21 & 52 & 11.25 \\
Education in years & 12 & 5 & 21 & 4.40 \\
Number of children & 2 & 0 & 4 & 1.33 \\
Leisure-time spent in park per week in minutes: & 35 & 25 & 60 & 9.43 \\
Male & 40 & 30 & 60 & 8.50 \\
Female & 35 & 25 & 50 & 7.73 \\
Monthly income in Pakistani Rupees (PKR) & 40,250 & 15,000 & 150,000 & $41,090.69$ \\
or & & or & & 265.43 \\
Monthly income in US Dollars (USD) & 260 & 97 & 969 & \\
\hline
\end{tabular}

Source Survey 2019

two. Furthermore, $48 \%$ of the respondents were living as married couple, while the remainder was single, widowed, separated or divorced. The sample average monthly income amounted to 260 US \$, approximately.

\section{Leisure-time and subjective well-being}

\section{The model}

Following Bruni and Porta (2005, 2007), Stutzer and Frey (2002) and Frash Jr. et al. (2016), the model we applied to evaluate subjective well-being (SWB) among park visitors in Pakistan took the following form:

$$
\begin{aligned}
& S W B_{i}=\beta_{0}+\beta_{1}\left(\text { sex }_{i}\right)+\beta_{2}\left(\text { age }_{i}\right)+\beta_{3}\left(\text { age }_{i}\right)^{2}+\beta_{4} \ln \left(\text { leisure }- \text { time spent in park per week } k_{i}\right) \\
& +\beta_{5}\left(\text { education }_{i}\right)+\beta_{6} \ln \left(\text { income }_{i}\right)+\beta_{7}\left({\text { number of } \left.\text { children }_{i}\right)}\right. \\
& +\beta_{8}\left(\text { marital status }_{i}\right)+\beta_{9}\left(\text { region }_{i}\right)+\varepsilon_{i}, i=1 \ldots n
\end{aligned}
$$

Our dataset provided different potential determinants of SWB which are incorporated in the regression model. ${ }^{4}$ As mentioned above, the SWB measure is based on an ordinal scale, which allows for estimating (1) as an ordered probit regression model. More specifically, the regressors were: sex, years of age, weekly leisure-time

\footnotetext{
${ }^{4}$ Also see, Angeles (2009), Frey (2008) and Shams (2016) for further information about SWB and its determinants and estimation, please.
} 
Table 3 Specification error test: Baseline Model (1)

\begin{tabular}{lll}
\hline Specification error test & & \\
\hline Number of obs & $=$ & 400 \\
LR $\chi^{2}(2)$ & $=$ & 67.50 \\
Prob $>\chi^{2}$ & $=$ & 0.0000 \\
Pseudo $R^{2}$ & $=$ & 0.6498 \\
Log likelihood & & -18.1926 \\
\hline Dependent variable: SWB & Coef & \\
\hline Independent & & Robust \\
Variable & & SE \\
\hline -hat & $0.8736^{* * *}[0.000]$ & 0.2362 \\
-hatsq & $0.0410[0.242]$ & 0.0351 \\
/cut1 & -4.6786 & 1.2512 \\
/cut2 & -1.1955 & 0.5932 \\
/cut3 & 2.6672 & 0.8563 \\
\hline
\end{tabular}

$\dagger, *, * *$ and $* * *$ denote statistical significance at $10 \%, 5 \%, 1 \%$ and $0.1 \%$ levels, respectively; $p$ values are given in square brackets

spent in park measured in minutes and expressed in natural logs, years of education, the park visitor's monthly absolute income (in nominal terms) measured in Pakistani Rupees (PKR) and expressed in natural logs, number of children, marital status and regional background of the park visitor $i{ }^{5}$ The regional dimension of the dataset was captured by three mutually exclusive dummy variables for park visitors based in Punjab, Sindh and Khyber Pukhtunkhuwa province, respectively. The baseline category referred to the park visitors living in the province of Balochistan. There were also some dichotomous dummy variables such as: sex and marital status. Those acquired the value of 1 if the visitor was female or living as a married couple and 0 otherwise. Age effects were allowed to be non-linear.

The results of specification tests for Model (1) are reported in Table 3. The linktest suggests that the model is properly specified. There are no omitted-variables and one should not be able to find any additional predictors that are statistically significant except by chance. In other words, we may infer that no irrelevant variable has been included in the model as the link function of the Model (1) appears to be correctly specified.

\footnotetext{
${ }^{5}$ Note that children were considered here as individuals living in a household with their parents at an age of less than 16 years old.
} 
Table 4 Baseline results

\begin{tabular}{|c|c|c|}
\hline \multicolumn{3}{|l|}{ Ordered probit regression } \\
\hline Number of obs & $=$ & 400 \\
\hline $\operatorname{LR} \chi^{2}(10)$ & $=$ & 66.18 \\
\hline Prob $>\chi^{2}$ & $=$ & 0.0000 \\
\hline Pseudo $R^{2}$ & $=$ & 0.6370 \\
\hline Log likelihood & $=$ & -18.8560 \\
\hline \multicolumn{3}{|l|}{ Dependent variable: SWB } \\
\hline Independent & Coef & Robust \\
\hline Variable & & Std. Err \\
\hline Female & $-2.0991 * *$ & 0.7887 \\
\hline Age & $-0.3794 *$ & 0.1845 \\
\hline Age Squared & $0.0055^{*}$ & 0.0024 \\
\hline Log of leisure-time & $3.7397 * *$ & 1.4821 \\
\hline Years of education & $0.1536^{*}$ & 0.0798 \\
\hline Log of monthly income & $1.3346^{\dagger}$ & 0.7673 \\
\hline No. of children & $-4.7909 * * *$ & 1.1991 \\
\hline \multicolumn{3}{|l|}{ Marital status } \\
\hline Married couple & $-12.2758 * * *$ & 3.0934 \\
\hline \multicolumn{3}{|l|}{ Region } \\
\hline Punjab & 0.7643 & 0.8347 \\
\hline Sind & 0.4178 & 0.8530 \\
\hline KPK & 0.1058 & 0.7957 \\
\hline Baluchistan & Reference group & \\
\hline /cut1 & -4.3920 & 3.9675 \\
\hline /cut2 & -1.0001 & 3.5521 \\
\hline /cut3 & 1.7136 & 3.6014 \\
\hline
\end{tabular}

$\dagger, *, * *$ and $* * *$ denote statistical significance at $10 \%, 5 \%, 1 \%$ and $0.1 \%$ levels, respectively

\section{Results and discussion}

\section{Results}

The estimation results for our baseline Model (1) are shown in Table 4. A positive coefficient shows that with one unit increase in the given control variable, the chance of achieving a higher outcome of SWB, that is ranked as 3 or 4 in our case, increases; on the other hand, a negative coefficient signals a lower ranked outcome of SWB which is rated here as 1 or 2 . Table 5 reports the marginal effects of the ordered probit regression analysis. The results are consistent with our baseline results given in Table 4.

According to Stutzer and Frey (2002), age, health and financial factors are important determinants of economic well-being. Easterlin (2006), using US 
Table 5 Ordered probit analysis: Marginal effects, baseline Model (1)

\begin{tabular}{|c|c|c|c|c|c|c|c|c|}
\hline \multirow{2}{*}{$\begin{array}{l}\text { Outcome: } \\
\text { SWB } \\
\text { Variable }\end{array}$} & \multicolumn{2}{|l|}{ (1) } & \multicolumn{2}{|l|}{ (2) } & \multicolumn{2}{|l|}{ (3) } & \multicolumn{2}{|l|}{ (4) } \\
\hline & $d_{\mathrm{y}} / d_{\mathrm{x}}$ & SE & $d_{\mathrm{y}} / d_{\mathrm{x}}$ & SE & $d_{\mathrm{y}} / d_{\mathrm{x}}$ & $\mathrm{SE}$ & $\mathrm{dy} / \mathrm{dx}$ & $\mathrm{SE}$ \\
\hline Female $^{x}$ & 0.0073 & 0.0152 & $0.6964 * * *$ & 0.1862 & $-0.6450 * * *$ & 0.1889 & -0.0587 & 0.0633 \\
\hline Age & 0.0005 & 0.0014 & $0.1509 *$ & 0.0742 & $-0.1476^{*}$ & 0.0752 & -0.0038 & 0.0061 \\
\hline AgeSquared & $-7.14 \mathrm{E}-06$ & 0.0000 & $-0.0022^{*}$ & 0.0010 & $0.0022 *$ & 0.0010 & $5.47 \mathrm{E}-05$ & 0.0001 \\
\hline $\begin{array}{l}\text { Log of leisure- } \\
\text { time }\end{array}$ & -0.5658 & 0.5184 & -0.0060 & 0.4792 & $0.5662 * *$ & 0.1962 & 0.0057 & 0.0102 \\
\hline $\begin{array}{l}\text { Years of edu- } \\
\text { cation }\end{array}$ & -0.0002 & 0.0006 & $-0.0611 \dagger$ & 0.0319 & $0.0597 \dagger$ & 0.0320 & 0.0015 & 0.0026 \\
\hline $\begin{array}{l}\text { Log of } \\
\text { monthly } \\
\text { income }\end{array}$ & $-1.18 \mathrm{E}-06$ & 0.0000 & $-0.5324 \dagger$ & 0.3056 & $0.5241 \dagger$ & 0.3087 & 0.0083 & 0.0154 \\
\hline No. of children & 0.0062 & 0.0177 & $1.9051^{* * * *}$ & 0.4905 & $-1.8639 * * *$ & 0.5382 & -0.0474 & 0.0759 \\
\hline $\begin{array}{l}\text { Married cou- } \\
\text { plex }\end{array}$ & 0.7572 & 0.5983 & 0.0631 & 0.0671 & $-0.8188 * * *$ & 0.1125 & -0.1181 & 0.0825 \\
\hline \multicolumn{9}{|l|}{ Region } \\
\hline Punjab $^{\times}$ & $-2.23 \mathrm{E}-06$ & 0.0000 & -0.2897 & 0.2853 & 0.2874 & 0.2842 & 0.0023 & 0.0050 \\
\hline $\operatorname{Sind}^{x}$ & $-1.95 \mathrm{E}-07$ & 0.0000 & -0.1652 & 0.3306 & 0.1626 & 0.3235 & 0.0026 & 0.0089 \\
\hline $\mathrm{KPK}^{\times}$ & $-6.25 \mathrm{E}-08$ & 0.0000 & -0.0422 & 0.3171 & 0.0417 & 0.3131 & 0.0005 & 0.0041 \\
\hline
\end{tabular}

1. $\dagger, *, * *$ and $* * *$ denote statistical significance at $10 \%, 5 \%, 1 \%$ and $0.1 \%$ levels, respectively. $2 .(\times)$ indicates discrete change of a dummy variable from 0 to 1

Marginal effects, ordered probit regression

$\mathrm{y}=\operatorname{Pr}(\mathrm{SWB}==1)($ predict, $\mathrm{p}$ outcome $(1))=0.0004$

$\mathrm{y}=\operatorname{Pr}(\mathrm{SWB}==2)($ predict, $\mathrm{p}$ outcome $(2))=0.5018$

$\mathrm{y}=\operatorname{Pr}(\mathrm{SWB}==3)($ predict, $\mathrm{p}$ outcome $(3))=0.4945$

$\mathrm{y}=\operatorname{Pr}(\mathrm{SWB}==4)($ predict, $\mathrm{p}$ outcome $(4))=0.0033$

survey data reports that both financial well-being and health are U-shaped in age. Similarly, our results reveal that our well-being metric, i.e. subjective well-being (in Table 4) and (in Table 6), follows U-shaped patterns in age with statistical turning points of 34 and 33 years of age, respectively. Similarly, Knight et al. (2009) for rural China; Blanchflower (2008) for USA and Europe find a U-shaped age-happiness profiles. Obviously, age related turning points of happiness (or subjective well-being) might vary with respect to time and regional context of the study. For instance, according to Blanchflower (2008), for US and European panel data, the turning point of happiness is related to mid or late forty years of age.

However, as far as gender effects are concerned, our results are quite opposite to similar studies on many advanced economies. For instance, our baseline results (in Table 4), show a significant negative effect of being a female on SWB. Even though there are differences in magnitude with respect to gender, women tend to self-reporting lower levels of subjective well-being compared to men (referred to 
Table 6 The mediating role of health satisfaction

\begin{tabular}{|c|c|c|}
\hline \multicolumn{3}{|l|}{ Ordered probit regression } \\
\hline Number of obs & $=$ & 400 \\
\hline $\operatorname{LR} \chi^{2}(11)$ & $=$ & 70.02 \\
\hline Prob $>\chi^{2}$ & $=$ & 0.0000 \\
\hline Pseudo $R^{2}$ & $=$ & 0.6460 \\
\hline Log likelihood & $=$ & -19.1835 \\
\hline \multicolumn{3}{|l|}{ Dependent variable: SWB } \\
\hline Independent & Coef & Robust \\
\hline Variable & & Std. Err \\
\hline Female & $-2.5663 * *$ & 0.9666 \\
\hline Age & $-0.4268 *$ & 0.1934 \\
\hline AgeSquared & $0.0064 * *$ & 0.0026 \\
\hline Log of leisure-time & 0.1397 & 0.2080 \\
\hline Years of education & $0.2593 *$ & 0.1235 \\
\hline Log of monthly income & $1.3553^{\dagger}$ & 0.7559 \\
\hline No. of children & $-5.4263^{* * *}$ & 1.2715 \\
\hline \multicolumn{3}{|l|}{ Marital status } \\
\hline Married couple & $-14.7578 * * *$ & 3.6707 \\
\hline \multicolumn{3}{|l|}{ Mediator } \\
\hline Health satisfaction & $5.0416 * *$ & 1.8705 \\
\hline \multicolumn{3}{|l|}{ Region } \\
\hline Punjab & 0.7706 & 0.8403 \\
\hline Sind & 0.4512 & 0.8608 \\
\hline KPK & 0.1023 & 0.7955 \\
\hline Baluchistan & Reference group & \\
\hline /cut1 & -3.4428 & 4.4771 \\
\hline /cut2 & -2.5641 & 4.3467 \\
\hline /cut3 & 2.6394 & 4.3474 \\
\hline
\end{tabular}

$\dagger, *, * *$ and $* * *$ denote statistical significance at $10 \%, 5 \%, 1 \%$ and $0.1 \%$ levels, respectively

Tables 4 and 6). On the other hand, in USA and in most of the European countries, females tend to be happier compared to their male counterparts (Blanchflower 2008).

On a more general note, our results confirm several findings commonly established in the happiness literature. For instance, SWB is higher among relatively educated and richer individuals. Education empowers people and enhances their capabilities to have access to better jobs, public services and improved livelihoods (Sen 1997). Similarly, Guardiola and Garcia-Munoz (2011) for rural Guatemala; Knight et al. (2009) for rural China; Kingdon and Knight (2006) for South Africa; Rojas (2004, 2008) for Mexico and Pradhan and Ravallion (2000) for Jamaica and Nepal, conclude that education; income and access to public goods and services like parks 
and hospitals contribute positively to quality of life (QoL). Our results are in line with the above-mentioned studies such that education has a positive and significant impact on individual's general well-being. Similarly, our results reveal that richer individuals tend to enjoy better life. Moreover, our results confirm that more leisuretime spent in parks adds to the quality of life in general and particularly in terms of greater health satisfaction as shown in Tables 4 and 6, respectively.

On the other hand, SWB decreases with an increasing number of children and being a married couple. In contrast, Knight et al. (2009), analyzing national household survey data on subjective well-being in rural China suggest that married couples tend to be happier compared to those living as single, widow, separated or divorced. Similarly, many studies based on European countries found married couples to be happier than those who were not living as married couples (Bruni and Porta 2005, 2007). Moreover, many studies in the happiness literature include children as one of the explanatory variables of life satisfaction, but the results obtained are conflicting. For instance, some authors find a negative impact of children on household's happiness (Blanchflower 2008; Tella et al. 2003), while others find a positive (Stutzer and Frey 2006) or no effect (Clark 2006; Clark et al. 2008).

Summing up, our results confirm that education, income and leisure-time spent in parks improve QoL in general as shown in Table 4, but more specifically the leisuretime influences the health satisfaction of the parks visitors which in turn affects their QoL, as shown in Table 6.

Beyond these results, we failed to confirm any significant regional effects on SWB across the four provinces of urban Pakistan as shown in Tables 4 and 6.

\section{Discussion}

This study examines the impact of spending leisure-time in parks on subjective wellbeing, and health satisfaction among different park users in Pakistan. Differences are measured in terms of relationship status, education level, economic status, age, sex and other demographic variables. Generally, higher levels of subjective well-being are found among those who are well-educated and with a better economic position. One possible explanation for the positive relationship could be that educated and richer people are usually capable to look after themselves and have access to public goods and services like parks and hospitals, which contributes positively to QoL. On the other hand, Kahneman and Krueger (2006) analyzing US data observed that richer individuals usually put more time in work which in turn negatively affect their work-life balance, overall well-being and health.

Blanchflower's (2008) evidence for industrialized countries suggests that wellbeing depends positively on being a married couple but is decreasing among people having children; as for age, a U-shaped behavior is observed. In contrast, our study's results reveal that being a married couple has negative impact on subjective well-being. Similarly, having a higher number of children has negative influence on subjective well-being of the park users. Moreover, we find that subjective well-being is U-shaped in age with statistical turning points of 34 and 33 years of age, as given in Tables 4 and 6, respectively. These findings may be connected. After 
all, children are seen as an extra burden at least in terms of responsibility on part of their parents or married couples, which in turn may negatively influence their personal lives including their leisure-time, personal health and overall well-being. Similarly, younger adults (who are in their early thirty years of age) usually face more challenges in terms of their personal, professional and family lives compared to older adults, which may adversely affect their work-life balance in general and particularly their leisure-time, health and overall well-being. A relatively fair distribution of time devoted to work and personal life including leisure-time activities reduces stress and improves quality of life (Greenhaus et al. 2003). Similarly, Kim and Jin (2018) examined relationship between urban parks and subjective well-being using happiness data. The authors found that urban parks are positively related with residents' subjective well-being. Benefits of urban parks for elderly people are found to be much greater than those for young adults. The authors suggest that providing urban parks may improve happiness of the elderly population in Seoul, South Korea.

Our study reports generally higher levels of subjective well-being among individuals who are in their late thirty years of age, well-educated and with a better economic position. These factors did not demonstrate a statistically significant relationship with the amount of time spent in parks. The amount of weekly leisure-time spent in parks has positive relationship with subjective well-being and health satisfaction, notwithstanding differences in magnitude as shown in Tables 4 and 6. As far as the variable sex is concerned, we observe men self-reporting more subjective well-being than women. One possible explanation for the women's negative effect could be that women usually work both at home and at work place and thus face difficulties in achieving work-life balance and usually suffer from work-imbalance particularly, which in turn affect their health or general well-being, adversely (Hyman and Summers 2004).

In general, our study revealed that the amount of weekly leisure-time spent in parks had positive and statistically significant relationship with subjective wellbeing and self-reported health satisfaction of the park users. In contrast, Lee and Maheswaran (2011) in a meta-analysis conclude that the evidence for the park use and health as well as well-being relationship is weak. The authors found that apart from the environmental factors such as the quality and accessibility of green space; user determinants such as age, gender, ethnicity and the perception of safety are also important for the park use. According to Brajša-Žganec et al. (2011) the quality of life is determined by both the objective factors, such as age and gender and also with the subjective perception of factors which influence life satisfaction. The overall results show that involvement in leisure activities contributes to subjective wellbeing across different age and gender groups. Lapa (2013) finds a positive linear relationship between life satisfaction, leisure satisfaction and perceived freedom in leisure of park recreation participants in Antalya, Turkey. The author reports no difference between leisure satisfaction and a significant difference between perceived freedom in leisure across genders. For instance, the results show that women report higher perceived freedom in leisure as compared to men. Similarly, the author observes a significant difference between leisure satisfaction and perceived freedom in leisure across the participants from different age and income groups. For instance, the results show that the participants under forty years of age and those from higher 
Table 7 Specification error test: baseline Model (2)

\begin{tabular}{lll}
\hline Specification error test & & \\
\hline Number of obs & $=$ & 400 \\
LR $\chi^{2}(2)$ & $=$ & 70.90 \\
Prob $>\chi^{2}$ & $=$ & 0.0000 \\
Pseudo $R^{2}$ & $=$ & 0.6541 \\
Log likelihood & & -18.7431 \\
\hline Dependent variable: SWB & Coef & \\
\hline Independent & & Robust \\
Variable & & SE \\
\hline -hat & $0.9571^{* * *}[0.000]$ & 0.2270 \\
-hatsq & $0.0305[0.352]$ & 0.0328 \\
/cut1 & -2.9574 & 1.0118 \\
/cut2 & -2.2741 & 0.7424 \\
/cut3 & 2.8078 & 0.8548
\end{tabular}

$\dagger, *, * *$ and $* * *$ denote statistical significance at $10 \%, 5 \%, 1 \%$ and $0.1 \%$ levels, respectively; $p$ values are given in square brackets

income groups report higher leisure satisfaction and perceived freedom in leisure. Lee et al. (2015) argue that in reality the relationship among the park use and health and well-being is more likely to be complex. The authors explain that it is likely that the health benefits gained are a result of use of urban parks/urban green spaces and not just from their presence. Our study thus reaffirms practical implications for policy makers looking to encourage park visitation or park use for leisure activities in general and particularly for females through park facilitation, which apply equally across the all four provinces of Pakistan.

\section{Leisure-time and subjective well-being: the mediating role of health satisfaction}

Building upon Model (1), we hypothesized the Model (2) to evaluate the mediating role of health satisfaction between leisure-time and subjective well-being.

$$
\begin{aligned}
& S W B_{i}=\beta_{0}+\beta_{1}\left(\text { sex }_{i}\right)+\beta_{2}\left(\text { age }_{i}\right)+\beta_{3}\left(\text { age }_{i}\right)^{2}+\beta_{4} \ln \left(\text { leisure - time spent in park per week }{ }_{i}\right)
\end{aligned}
$$

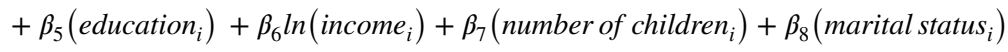

$$
\begin{aligned}
& +\beta_{9}\left(\text { health satisfaction }_{i}\right)+\beta_{10}\left(\text { region }_{i}\right)+\varepsilon_{i}, i=1 \ldots n
\end{aligned}
$$

Results are shown in Table 6. We observed that health satisfaction fully mediated the relationship between leisure-time and subjective well-being. Previous studies in Pakistan have shown positive relationship between health and subjective well-being in general (Shams 2016), however, it has not been fully examined within the context of leisure-time spent in the parks. The study contributes to the existing literature by analyzing the mediating role of health satisfaction between leisure-time and 
subjective well-being with particular reference to urban parks visitors in Pakistan. The specification error test (link test) corresponding to Model (2) is reported in Table 7. The test confirms that the model is specified correctly.

\section{Concluding remarks and the way forward}

The study is based on micro data of park visitors in urban Pakistan. The aim of the study is to link the weekly leisure-time spent in park with the subjective well-being of the park visitors. The study employs methods from the economics of happiness literature, taking weekly leisure-time spent in park as a predictor of park visitor's self-reported health satisfaction (Bruni and Porta 2005, 2007). Our subjective wellbeing scale is a holistic approach to well-being capturing all domains of life and may overlap potentially with the "Satisfaction With Life Scale" (SWLS) by Pavot and Diener (2008), which is an alternative, reliable indicator.

We contribute to the existing literature on happiness studies by identifying the determinants of happiness or subjective well-being among the park visitors in urban Pakistan. Our study fills an important gap in the literature by comparing well-being of those from a developing, more specially an Asian country like Pakistan to other Western as well as Eastern countries of the world.

The findings of our study are in line with some common findings in the literature. For instance, relatively educated or richer individuals report higher well-being. Similarly, we observe a U-shaped curve of happiness according to the increase in age of the respondents (Blanchflower, 2008). However, there are few exceptions that contradict the U-shaped behavior of happiness with increasing age. For instance, Horley and Lavery (1995) report subjective well-being to be increasing up to 74 years of age but decreasing above 74 years of age.

Furthermore, in line with the evidence on advanced countries, we find SWB to be decreasing with an increase in the number of children. On the other hand, unlike the evidence typically reported on advanced countries, we find evidence for SWB to be lower among married couples and among women compared to men (Bruni and Porta 2005, 2007; Blanchflower 2008). Our findings suggest that the length of stay in urban parks as part of leisure activities has positive effect on SWB (or selfreported quality of life, or happiness) of park users. Park managers need to consider a heterogeneous profile of urban park users and may design the park services according to the needs of diverse socio-economic and demographic backgrounds of urban inhabitants and park users in the study area.

In general, our results reveal that higher leisure-time spent in park have positive influence on individual's self-reported life satisfaction (or SWB) and particularly health satisfaction (HS) on pure subjective grounds; in other words we may say that the health satisfaction mediate the relationship between weekly leisure-time spent in park and subjective well-being among the park visitors in the study area. This may also help in understanding a healthy work-life balance for improving the quality of life particularly of the female segment of the society. Policymakers or the city planners should hence put more emphasis on park facilitation and its provision in general and particularly for females (e.g. Ladies Parks) to encourage park use or frequency 
of visitation and park time for greater happiness and better quality of life in general and particularly in terms of health satisfaction. Our results apply equally across the four provinces of urban Pakistan. However, they are probably more general and may offer important insights as to how to strengthen health outcomes in the developing world-particularly with new challenges arising from Covid-19. Secondly, our results provide options for future studies on work-life imbalance and well-being across the genders in different countries of the world.

Data availability The manuscript data will not be disclosed due to confidentiality reasons.

\section{Disclosures}

Conflict of interest We declare that there is no conflict of interest. All remaining errors are our own.

Ethical standards The data have been collected by means of a survey with the approval of the Shaheed Benazir Bhutto Women University Peshawar Pakistan, the College Ethics Committee/University Ethics Committee.

Informed consent The research is purely conducted on academic basis with informed consent of the University Ethics Committee and the respondents.

\section{References}

Angeles L (2009) Do children make us happier? Discussion Paper Series University of Glasgow. Retrieved from https://EconPapers.repec.org/RePEc:gla:glaewp:2009 10.

Assali IM (2015) Augmenting urban parks in Bahrain for the improvement of citizens' health. Int J Res Eng Technol 4(11):140-152

Beck H (2009) Linking the quality of public spaces to quality of life. J Place Manag Dev 2(3):240-248

Blanchflower DG (2008) International evidence on well-being. NBER Working Paper No. w14318. Retrieved from https://www.nber.org/papers/w14318.

Brajša-Žganec A, Merkaš M, Šverko I (2011) Quality of life and leisure activities: how do leisure activities contribute to subjective well-being? Soc Indic Res 102:81-91. https://doi.org/10.1007/ s11205-010-9724-2

Bruni L, Porta PL (2005) Economics and happiness - framing the analysis. Oxford University Press, Oxford

Bruni L, Porta PL (2007) Handbook on the economics of happiness. Edward Elgar Publishers, Northampton

CIA (2019) The World Factbook. Retrieved from https://www.cia.gov

Clark AE (2006) Born to be mild? Cohort effects do not explain why well-being is U-shaped in age. PSE Working Papers n-2006-35. Retrieved from https://halshs.archives-ouvertes.fr/halshs-00590307/ document

Clark AE, Frijters P, Schields MA (2008) Relative income, happiness and utility: an explanation for the Easterlin paradox and other puzzles. J Econ Lit 46(1):95-144

Diener E (2009) Subjective well-being. In: Diener E. (eds), The Science of Well-Being. Social Indicators Research Series, (Vol. 37, pp. 11-58). Springer, Dordrecht.

Easterlin R (2006) Life cycle happiness and its sources: Intersections of psychology, economics and demography. J Econ Psychol 27:463-482

Frash RE Jr, Blose JE, Norman WC, Patience M (2016) Healthy parks, happy people: an exploratory study of a county park system. J Park Recreat Admin 34(1):84-102. https://doi.org/10.18666/ JPRA-2016-V34-11-6801

Frey B (2008) Happiness: a revolution in economics. The MIT Press, Cambridge

Gies, E. (2006). The Health Benefits of Parks. The Trust for Public Land. 
Greenhaus JH, Collins KM, Shaw JD (2003) The relation between work-family balance and quality of life. J Vocat Behav 63(3):510-531. https://doi.org/10.1016/S0001-8791(02)00042-8

Guardiola J, Garcia-Munoz T (2011) Fulfillment of basic needs from a subjective point of view in rural Guatemala. Int J Soc Welf 20(4):393-403. https://doi.org/10.1111/j.1468-2397.2010.00758.x

Hajmirsadeghi RS (2012) The influence of urban parks on sustainable city via increase quality of life. Elixir Sustain 51:10766-10770

Horley J, Lavery J (1995) Subjective well-being and age. Soc Indic Res 34(2):275-282. https://doi.org/ 10.1007/BF01079200

Hussain G, Nadeem M, Younis A, Riaz A, Khan MA, Naveed S (2010) Impact of public parks on human life: a case study. Pak J Agric Sci 47(3):225-230

Hyman J, Summers J (2004) Lacking balance? Work-life employment practices in the modern economy. Person Rev 33(4):418-429. https://doi.org/10.1108/00483480410539498

Kaczynski A, Henderson KA (2007) Environmental correlates of physical activity: a review of evidence about parks and recreation. Leis Sci 29(4):315-354

Kahneman D, Krueger AB (2006) Developments in the measurement of subjective well-being. J Econ Perspect 20(1):3-24 https://doi.org/10.1257/089533006776526030

Kim D, Jin J (2018) Does happiness data say urban parks are worth it? Landsc Urban Plan 178:1-11

Kingdon GG, Knight J (2006) Subjective well-being poverty vs income poverty and capabilities poverty? J Dev Stud 42(7):1199-1224. https://doi.org/10.1080/00220380600884167

Knight J, Song L, Gunatilaka R (2009) Subjective well-being and its determinants in rural China. China Econ Rev 20(4):635-649

Koohsari MJ, Mavoa S, Villianueva K, Sugiyama T, Badland H, Kaczynski AT, Owen N, Giles-Corti B (2015) Public open space, physical activity, urban design and public health: concepts, methods and research agenda. Health Place 33:75-82. https://doi.org/10.1016/j.healthplace.2015.02.009

Koramaz EK, Türkoglu H (2018) Measuring and understanding urban parks' contribution to quality of life in Istanbul. Soc Indic Res 138(1):335-351. https://doi.org/10.1007/s11205-017-1657-6

Lapa TY (2013) Life satisfaction, leisure satisfaction and perceived freedom of park recreation participants. Procedia Soc Behav Sci 93(21):1985-1993. https://doi.org/10.1016/j.sbspro.2013.10.153

Larson LR, Jennings V, Cloutier SA (2016) Public parks and well-being in urban areas of the United States. PLoS ONE 11(4):e0153211. https://doi.org/10.1371/journal.pone.0153211

Lee ACK, Maheswaran R (2011) The health benefits of urban green spaces: a review of the evidence. J Public Health 33(2):212-222. https://doi.org/10.1093/pubmed/fdq068

Lee ACK, Jordan HC, Horsley J (2015) Value of urban green spaces in promoting healthy living and well-being: prospects for planning. Risk Manage Healthcare Policy 8:131-137. https://doi.org/10. 2147/RMHP.S61654

Li C-L (2020) Quality of life: the perspective of urban park recreation in three Asian cities. J Outdoor Recreat Tour. https://doi.org/10.1016/j.jort.2019.100260

Liu H, Li F, Li J, Zhang L (2017) The relationships between urban parks, residents' physical activity, and mental health benefits: a case study from Beijing, China. J Environ Manage 190:223-230. https:// doi.org/10.1016/j.jenvman.2016.12.058

Maller C, Townsend M, St Leger L, Henderson-Wilson C, Pryor A, Prosser L, Moore M (2009) Healthy parks healthy people: the health benefits of contact with nature in a park context. George Wright Forum 26(2):51-83

Mitchell R, Popham F (2008) Effect of exposure to natural environment on health inequlalities: an observational population study. Lancet 372(9650):1655-1660. https://doi.org/10.1016/S0140-6736(08) 61689-X

MORI research for CABE Space (2004) Public attitudes to architecture and public space: transforming neighbourhoods. Retrieved from https://www.cabespace.org.uk.

Nasution AD, Zahrah W (2014) Community perception on public open space and quality of life in Medan, Indonesia. Procedia 153:585-594

Pakistan Bureau of Statistics (2017) 6th Population and Housing Census-2017. Government of Pakistan, Ministry of Statistics: Statistics Division.

Pavot W, Diener E (2008) The satisfaction with life scale and the emerging construct of life satisfaction. J Posit Psychol 3(2):137-152. https://doi.org/10.1080/17439760701756946

Pradhan M, Ravallion M (2000) Measuring poverty using qualitative perceptions of consumption adequacy. Rev Econ Stat 82(3):462-471

Rojas M (2004) Well-being and the complexity of poverty: a subjective well-being approach. Research Paper, United Nations University, WIDER no.2004/29. Retrieved from https://www.wider.unu.edu. 
Rojas M (2008) Experienced poverty and income poverty in mexico: a subjective well-being approach. World Dev 36(6):1078-1093. https://doi.org/10.1016/j.worlddev.2007.10.005

Sanchez-Triana E, Afzal J, Enriquez S (2014) Environmental impact assessment handbook for Pakistan. IUCN Pakistan, Islamabad

Sen A (1997) Editorial: human capital and human capability. World Dev 25(12):1959-1961. https://doi. org/10.1016/S0305-750X(97)10014-6

Shams K (2016) Developments in the measurement of subjective well-being and poverty: an economic perspective. J Happiness Stud 17(6):2213-2236. https://doi.org/10.1007/s10902-015-9691-z

Sturm R, Cohen D (2014) Proximity to urban parks and mental health. J Ment Health Policy Econ 17(1):19-24

Stutzer A, Frey B (2002) Happiness and economics. Princeton University Press, Princeton

Stutzer A, Frey BS (2006) Does marriage make people happy or do happy people get married? J SocioEcon 35(2):326-347. https://doi.org/10.1016/j.socec.2005.11.043

Taylor W, Floyd M, Whitt-Glover M, Brooks J (2007) Environmental justice: a framework for collaboration between the public health and parks and recreation fields to study disparities in physical activity. J Phys Act Health 4(1):S50-S63. https://doi.org/10.1123/jpah.4.s1.s50

Tella RD, MacCulloch RJ, Oswald AJ (2003) The macroeconomics of happiness. Rev Econ Stat 85(4):809-827. https://doi.org/10.1162/003465303772815745

Van Herzele A, de Vries S (2012) Linking green space to health: a comparative study of two urban neighbourhoods in Ghent, Belgium. Popul Environ 34:171-193. https://doi.org/10.1007/ s11111-011-0153-1

World Bank. (2013). 2013 World Bank Report. Retrieved from https://www.worldbank.org.

Yamane T (1967) Statistics: an introductory analysis, 2nd edn. Harper \& Row, New York 